This item was submitted to Loughborough's Research Repository by the author.

Items in Figshare are protected by copyright, with all rights reserved, unless otherwise indicated.

\title{
Application of diagnostic techniques to an experimental aircraft fuel rig
}

\section{PLEASE CITE THE PUBLISHED VERSION}

http://www.ifac-control.org/publications/ifac-papersonline.net

\section{PUBLISHER}

(C) Elsevier

\section{VERSION}

SMUR (Submitted Manuscript Under Review)

\section{LICENCE}

CC BY-NC-ND 4.0

\section{REPOSITORY RECORD}

Bennett, Paul J., John T. Pearson, A. Martin, Roger Dixon, M.C. Walsh, Mandeep Khella, and Roger M. Goodall. 2019. "Application of Diagnostic Techniques to an Experimental Aircraft Fuel Rig". figshare. https://hdl.handle.net/2134/3307. 
This item was submitted to Loughborough's Institutional Repository by the author and is made available under the following Creative Commons Licence conditions.

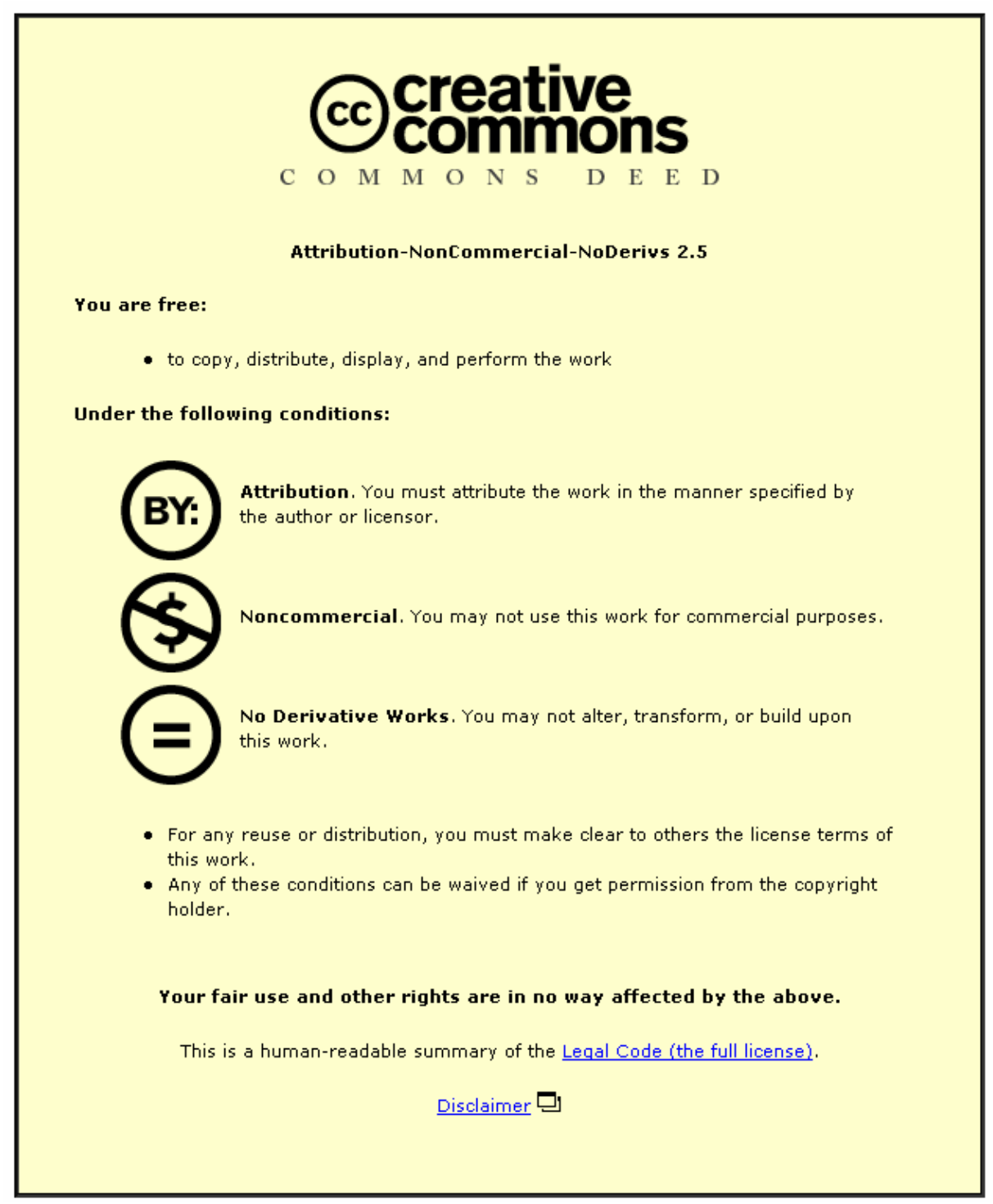

For the full text of this licence, please go to: http://creativecommons.org/licenses/by-nc-nd/2.5/ 


\title{
APPLICATION OF DIAGNOSTIC TECHNIQUES TO AN EXPERIMENTAL AIRCRAFT FUEL RIG
}

\author{
P.J.Bennett ${ }^{+}$, J.T.Pearson*, A.Martin", R.Dixon ${ }^{+}$, M.C.Walsh ${ }^{*}$, M.Khella ${ }^{*}$, and R.M.Goodall ${ }^{+}$ \\ *Systems Engineering Innovation Centre, BAE Systems, Sir Denis Rooke Building, Holywell Park, Loughborough \\ University, Loughborough, Leicestershire, LE11 3TU, Telephone +44(0)1509635251 \\ ${ }^{+}$Department of Electronic and Electrical Engineering, Loughborough University, Loughborough, Leicestershire, \\ LE11 3TU, Telephone +44(0)150922 7018
}

\begin{abstract}
An important issue for Aerospace and Defence Systems providers is how to reduce the risks associated with installing a new Fault Detection Tool (FDT) on a system. It is highly desirable that some degree of assessment, selection and validation is carried out before the FDT is integrated with the system. This paper describes the initial phases of a project to investigate the processes behind the assessment and validation using an Experimental Aircraft Fuel Rig (referred to as the Advanced Diagnostic Test-bed ADT). This paper also presents results from preliminary verification and validation work that has been used on a mathematical model of the ADT, and also some results from some initial diagnostic technique assessment that has been performed using real experimental data from the ADT and simulated data from mathematical models. Copyright (C) 2006 IFAC
\end{abstract}

Keywords: Aerospace, Fault Detection, Fault Diagnosis, Fault Isolation, Model Based.

\section{INTRODUCTION}

Aerospace and Defence Systems are becoming increasingly complex with higher component counts and ever more complicated components and subassemblies. Faults and failures are becoming harder to detect and isolate. The time that operators and maintenance technicians need to spend on faults is rising in direct relation to the complexity of the systems. With these increasing demands on reliability, maintainability and safety of systems, a wide range of fault detection and diagnostic methodologies have been proposed, and there has been considerable interest in the practical application of these fault diagnostic techniques. Reliable diagnostic techniques can contribute to reduced maintenance costs and, perhaps more importantly, to increased system availability. The selection and integration of an appropriate diagnostic tool has the potential to produce a reduction in life cycle costs for both the customer and the manufacturer. For autonomous systems on board fault diagnosis is vital as the human interface is no longer available to perform the function that needs to be performed in order to ensure the safe operation of the system.

An important issue for Aerospace and Defence Systems providers is how to reduce the risks associated with installing a new Fault Detection Tool (FDT) on a system. Several tools might be offered for consideration, some bespoke or internally developed, others being provided by third parties. It is highly desirable that some degree of assessment, selection and validation is carried out before the FDT is integrated with the system. This paper describes the initial phases of a project to investigate the assessment and validation of fault diagnostic tools and techniques. It describes the development of an Advanced Diagnostic Test-bed (ADT) and a Prognostic Health Management (PHM) laboratory at the Systems Engineering Innovation Centre (SEIC) which are being used for the validation and assessment of different diagnostic and fault isolation techniques and tools. 
The ADT is a representation of a fuel system of a modern aircraft and its associated electrical power supply. The test-bed consists of a number of tanks, pumps, flow meters, pressure sensors, level sensors, three-phase motors, inverters, voltage sensors, current sensors and other instrumentation. This allows for the implementation and investigation of a wide range of fault diagnostic tools and techniques. A comprehensive collection of different types of faults can be injected into the testbed, which also has the capability for reconfiguring its fluid and electrical systems in the event of such faults being detected and isolated.

This paper also presents results from preliminary verification and validation work that has been used on a mathematical model of the ADT, and also results from some initial diagnostic technique assessment that has been performed using real experimental data from the ADT and simulated data from the mathematical models.

\section{ADVANCED DIAGNOSTIC TESTBED DESCRIPTION}

The Advanced Diagnostic Test-bed (ADT) is a representation of a modern aircraft fuel system. A photograph of the ADT is shown below in figure 1 .

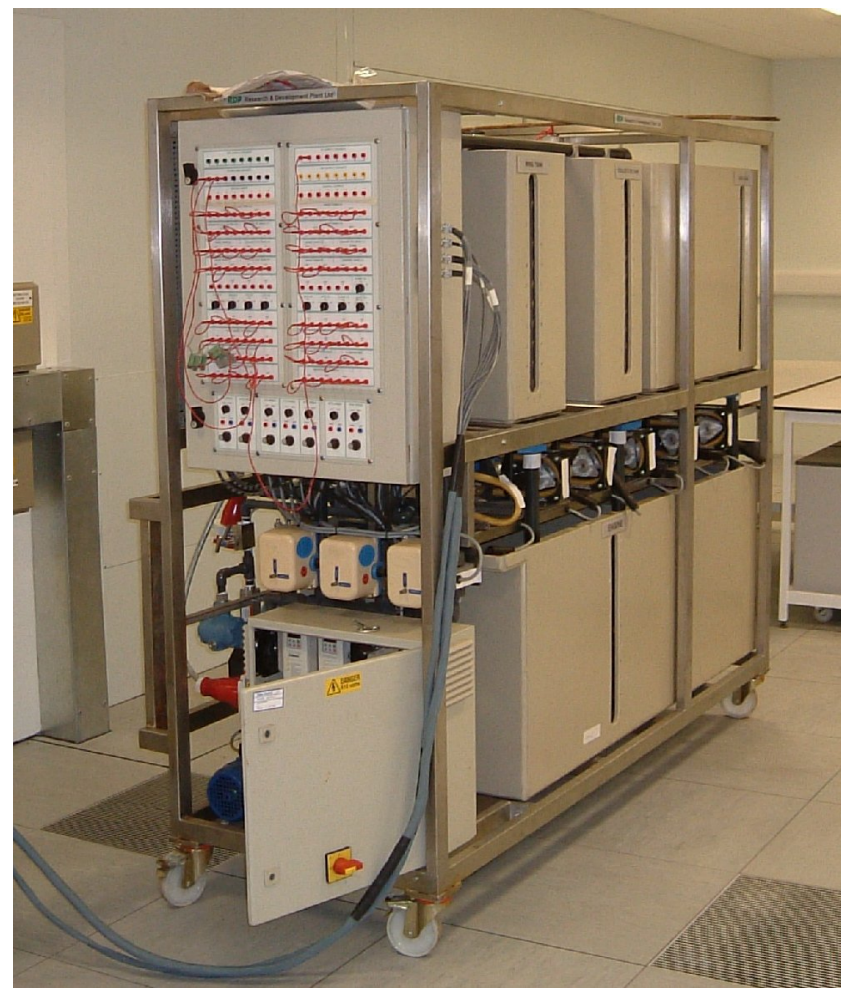

Fig 1. Advanced Diagnostic Test-bed ADT.

\subsection{ADT Structure}

The ADT consists of four tanks: a Wing Tank and a Main Tank, each of which is connected to the Collector Tank by two pumps (two Wing Tank pumps and two Main Tank pumps). The Collector Tank supplies the engine (represented by the fourth tank) via two collector pumps. Fig 2 shows a schematic of the ADT. Only the four tanks, six pumps and three flow-meters are shown for clarity.

Each tank is equipped with a temperature sensor, a level sensor as well as discrete level limit switches. Each pump is fitted with a pressure sensor, a discrete pressure switch and a speed sensor, and each pair of pumps is connected to a flow meter.

The piping arrangement between tanks and pumps is complex as there are a number of dual port and triple port electrically actuated valves which provide the ADT with the capability to reconfigure the flow paths in the event of a fault, for example a blockage or a failure in one of the pumps. There are also a number of temperature probes, microphones and accelerometers mounted on or in close proximity to the pumps. Clearly this extra instrumentation, along with the reconfiguration valves, would not normally be found on a conventional aircraft fuel system, but have been included to provide the ADT with capabilities that enable a wide range of fault diagnostic tools and techniques to be implemented and investigated.

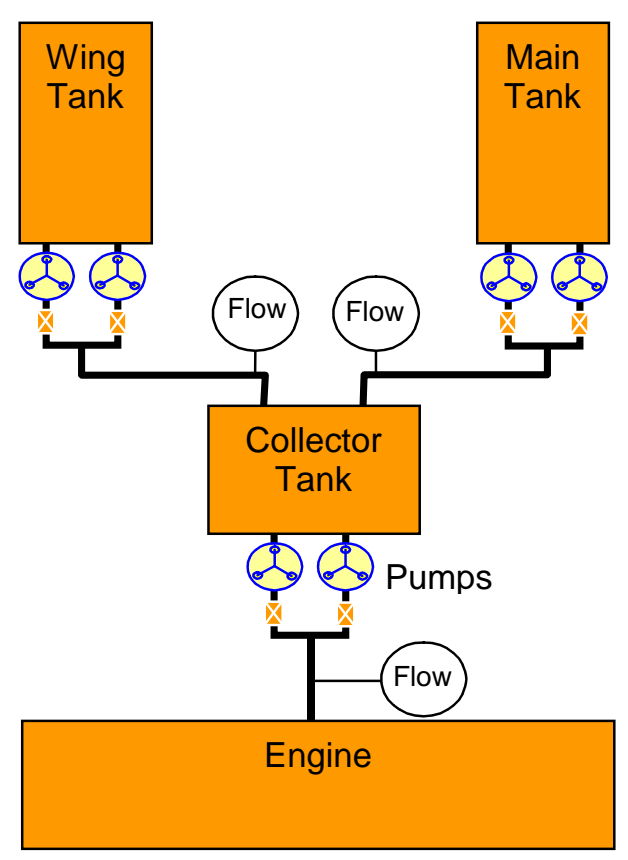

Fig 2. ADT Schematic

The electrical system for the ADT has also been designed to be a representation of an aircrafts electrical system. As such there is a primary and a secondary busbar. The pumps and the sensor power supplies can be switched between either busbar using electronically controlled relays providing a degree of reconfiguration and fault injection capability in the electrical system.

\subsection{ADT Control and Logging System}

The ADT is linked to a PC that performs three primary tasks (fig. 3). The first task is to log all the measurement data from the ADT sensors and control signals to the ADT. These are stored in a database that forms part of the overall Prognostic Health 
Management (PHM) facility. The second task is to run a fuel control algorithm; this is a relatively simple algorithm and is not described in detail in this paper. The final task relates to the implementation of the diagnostic functions.
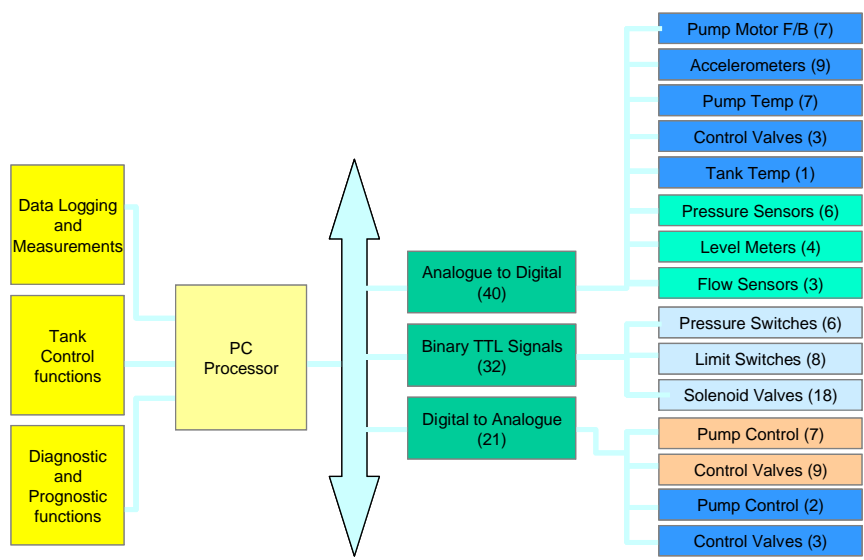

Fig 3. ADT Control and Data Logging.

\subsection{ADT Fault Injection}

A range of faults can be injected into the ADT, these include faults in the fluid sub-system, faults in the power supply sub-system and faults in the sensing sub-system. Table 1 is not an exhaustive list of possible faults, but does indicate some of the typical faults that can be injected into the ADT. These faults can be injected using the software running on the ADT PC, or they can be injected physically on the patch-board located on the end of the ADT. This patch-board enables all sensor signals to be manipulated in the following ways: i) physical disconnection, ii) set to full scale or $0 \mathrm{v}$, and iii) summation with a secondary signal, such as additional noise, a bias, or another function.

\begin{tabular}{|l|l|}
\hline \multicolumn{2}{|l|}{ Fluid Sub-system } \\
\hline $\mathrm{f}_{\mathrm{f} 1}$ & Flow Valve Stuck Open \\
\hline $\mathrm{f}_{\mathrm{f} 2}$ & Flow Valve Stuck Shut \\
\hline $\mathrm{f}_{\mathrm{f} 3}$ & Pump Fault \\
\hline $\mathrm{f}_{\mathrm{f} 4}$ & Isolation Valve Shut \\
\hline $\mathrm{f}_{\mathrm{f} 5}$ & Tank leak \\
\hline Power Sub-system \\
\hline $\mathrm{f}_{\mathrm{p} 1}$ & Primary Busbar fault \\
\hline $\mathrm{f}_{\mathrm{p} 2}$ & Secondary Busbar fault \\
\hline $\mathrm{f}_{\mathrm{p} 3}$ & Valve Actuation Power Supply fault \\
\hline $\mathrm{f}_{\mathrm{p} 4}$ & 5v Sensor Power Supply fault \\
\hline $\mathrm{f}_{\mathrm{p} 5}$ & 12v Sensor Power Supply fault \\
\hline Sensor Sub-system \\
\hline $\mathrm{f}_{\mathrm{s} 1}$ & Level Sensor open circuit fault \\
\hline $\mathrm{f}_{\mathrm{s} 2}$ & Pressure sensor open circuit fault \\
\hline $\mathrm{f}_{\mathrm{s} 3}$ & Flow meter open circuit fault \\
\hline $\mathrm{f}_{\mathrm{s} 4}$ & Level Switch open circuit fault \\
\hline $\mathrm{f}_{\mathrm{s} 5}$ & Voltage Sensor open circuit fault \\
\hline $\mathrm{f}_{\mathrm{s} 6}$ & Current Sensor open circuit fault \\
\hline $\mathrm{f}_{\mathrm{s} 7}$ & Pressure switch open circuit fault \\
\hline $\mathrm{f}_{\mathrm{s} 8}$ & Accelerometer open circuit fault \\
\hline $\mathrm{f}_{\mathrm{s} 9}$ & Microphone open circuit fault \\
\hline $\mathrm{f}_{\mathrm{s} 10}$ & Temperature Sensor open circuit fault \\
\hline $\mathrm{T}_{2}$ & T: List of Fauts \\
\hline
\end{tabular}

Table 1: List of Faults

\section{SYSTEM MODEL}

The main dynamics of the ADT of interest are those of the fluid system, and can be represented by equations for fluid height in the tanks, pressure and flow rate. The height and pressure of the fluid in the tank are defined by the equations below:-

$$
\begin{aligned}
& h(t)=\frac{\int\left(q_{\text {in }(t)}-q_{\text {out }(t)}\right) d t}{a} \\
& P(t)=\rho g h(t)
\end{aligned}
$$

The valve equation below gives the volumetric flow rate from the valve for a given pressure differential across the valve.

$$
q(t)=\frac{c_{v \cdot} y_{v(t)} \sqrt{\frac{\Delta P(t)}{v}}}{\rho}
$$

The pumps used on the ADT are peristaltic pumps, and these provide a flow which is directly proportional to the pump motor speed. The peristaltic pump used can provide a maximum of 6.3 $1 / \mathrm{m}$ at full motor speed (191 rpm). The defining equation for the peristaltic pump model is given below.

$$
q(t)=c \dot{\theta}
$$

Where:

$\mathrm{c}=$ motor speed to pump flow coefficient

$\dot{\theta}=$ pump motor speed (Revolutions Per Second)

$\mathrm{q}=$ volumetric flow rate $\left(\mathrm{m}^{3} / \mathrm{s}\right)$

$\mathrm{v}=$ specific volume $=1.0022 * 10^{-3} \mathrm{~m}^{3} / \mathrm{kg}$

$\rho=$ density $=997.78 \mathrm{~kg} / \mathrm{m}^{3}$

$\mathrm{c}_{\mathrm{v}}=$ valve conductance $=3.3167 * 10^{-5} \mathrm{~m}^{2}$

$\Delta \mathrm{P}=$ pressure difference $(\mathrm{Pa})$

$\mathrm{y}_{\mathrm{v}}=$ proportional valve opening

$\mathrm{a}=\operatorname{tank}$ area $\left(\mathrm{m}^{2}\right)$

$\mathrm{h}=$ height $(\mathrm{m})$

$\mathrm{q}=$ volumetric flow rate $\left(\mathrm{m}^{3} / \mathrm{s}\right)$

$\mathrm{g}=$ gravity $=9.81 \mathrm{~m} / \mathrm{s}^{2}$

$\mathrm{P}=$ pressure $(\mathrm{Pa})$

These equations were combined to form a standard state space model of the ADT

$$
\begin{aligned}
& \dot{\mathbf{x}}=\mathbf{A x}+\mathbf{B u} \\
& \mathbf{y}=\mathbf{C x}
\end{aligned}
$$

the input vector $u$ contains the control inputs to the six peristaltic pumps, and the state vector contains the height of the fluid levels in the Main, Wing and Collector tanks, and also the flow rates from the three tanks.

The model was validated using real data obtained from the ADT for a series of tests. Fig 4 shows the 
results for one such validation test, the results confirmed the mathematical model.

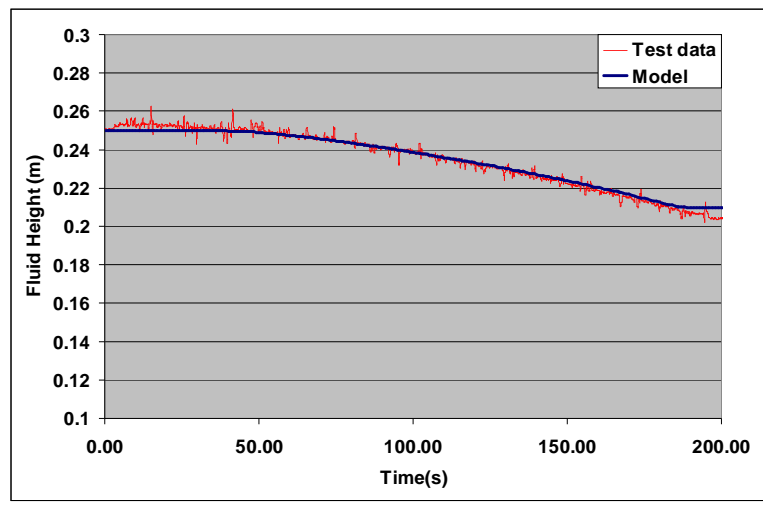

Fig 4: Comparison of fluid height in the main tank calculated by the mathematical model and compared to test data for fluid pumped by the main tank peristaltic pumps

\section{FAULT DIAGNOSTICS}

The fault diagnostic process can typically be divided into three key sub-processes: i) fault detection indicates the occurrence of a fault in the system, ii) fault isolation determines the type and/or location of the fault, and iii) fault reconfiguration corrects for the presence of the fault.

Model based approaches to fault diagnostics are well published in the literature, some key publications include Isermann [1984], Patton [2000], Gertler [1998] and Frank [1987].

These techniques generally compare the systems actual measurements with an estimate of the measurements generated by a mathematical model of the system. The resulting difference is called the residual signal, these are normally zero and become non-zero as a result of faults, disturbances, noise and modelling errors. The residuals are analysed to formulate a diagnostic decision (fault detection and isolation).

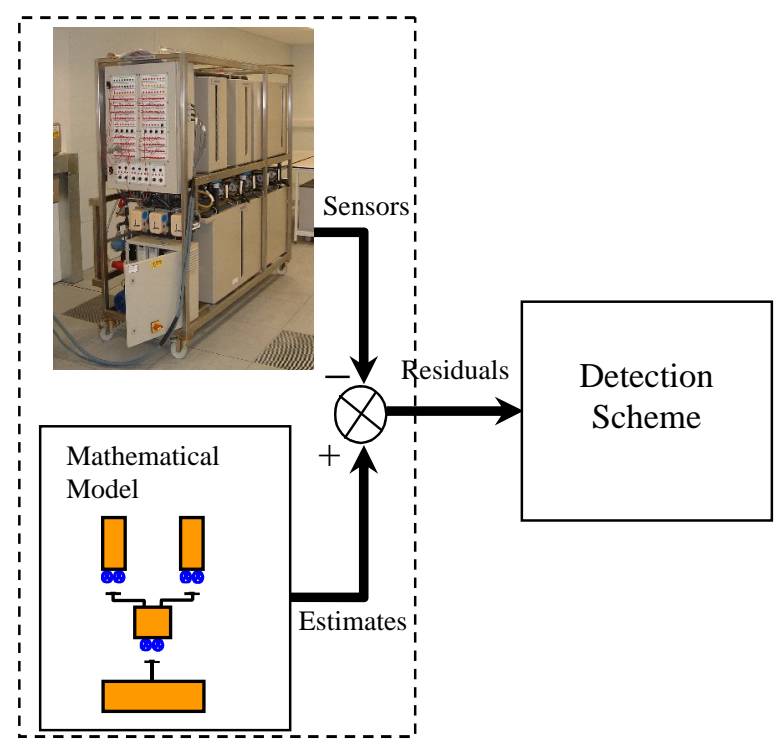

Fig 5. Fault Diagnostic Scheme
Fig 5 shows the arrangement of the diagnostic algorithm, with two main blocks described previously (residual generation and decision scheme). A majority of the published literature focuses on the residual generation process, however the design of the decision scheme is equally as important but often overlooked. One approach to the decision making scheme is to use thresholds, the selection of these thresholds is critical to the performance of the fault diagnostic scheme. In essence to be sensitive to faults while being insensitive to noise and modelling errors [Frank 1997].

\subsection{Kalman Filter Fault Detection Scheme}

This section describes the use of a Kalman filter for detecting a leak fault on the ADT. This is a simple preliminary implementation of the Kalman Filtering technique that has been used to prove the concept of fault diagnostics on the ADT. The technique will be enhanced in future stages of the project.

The main problem with this technique is that the Kalman Filter residuals are not only sensitive to faults, but also to errors in the model used.

The approach adopted is to model the system, in this case the Fuel Rig, by a set of linear first order differential equations. These are then arranged into the well know state space model form shown below:

$$
\begin{aligned}
& \dot{\mathbf{x}}=\mathbf{A x}+\mathbf{B u}+\boldsymbol{\omega} \\
& \mathbf{y}=\mathbf{C x}+\boldsymbol{v}
\end{aligned}
$$

A Kalman estimator for this system would be expressed in discrete time as

$$
\begin{aligned}
& \hat{\mathbf{x}}_{k+1 \mid k}=\Phi \hat{\mathbf{x}}_{k \mid k}+\Gamma \mathbf{u}_{k} \\
& \mathbf{e}_{k+1}=\mathbf{y}_{k+1}-\mathbf{C} \hat{\mathbf{x}}_{k+1 \mid k} \\
& \mathbf{x}_{k+1 \mid k+1}=\mathbf{x}_{k+1 \mid k}+\mathbf{G}\left(\mathbf{e}_{k+1}\right)
\end{aligned}
$$

where

$$
\Phi=\exp (\mathbf{A} d t), \text { and } \Gamma=(\Phi-\mathbf{I}) \mathbf{A}^{-1} \mathbf{B}
$$

The calculation of the Kalman gain matrix $\boldsymbol{G}$, is well known and involves the covariance matrix $\boldsymbol{Q}$, of the system uncertainty $\mathrm{w}$ and the covariance matrix $\boldsymbol{R}$ of the measurement noise $\boldsymbol{v}$, and the estimation state error co-variance matrix, $\boldsymbol{P}$. (The specific details will be omitted for brevity, see Gelb, 1989). The error, $\boldsymbol{e}$, is the residual signal (or the filter innovation) and has nominal dynamics governed by the choice of $\boldsymbol{G}$, ie. the bandwidth of the filter, and is driven by system uncertainty, measurement noise, and faults that may appear.

The Kalman Filter was used to detect a leak introduced in the main tank (fault $\mathrm{f}_{\mathrm{f} 5}$ ). Fig 6. shows the measured and estimated Main Tank flow rate and the corresponding residual. Fig 7. shows the measured and estimated Main Tank height and the corresponding residual. Fig 8. shows the leak 
introduced into the Main Tank and the leak detection signal produced by the Kalman Filter.

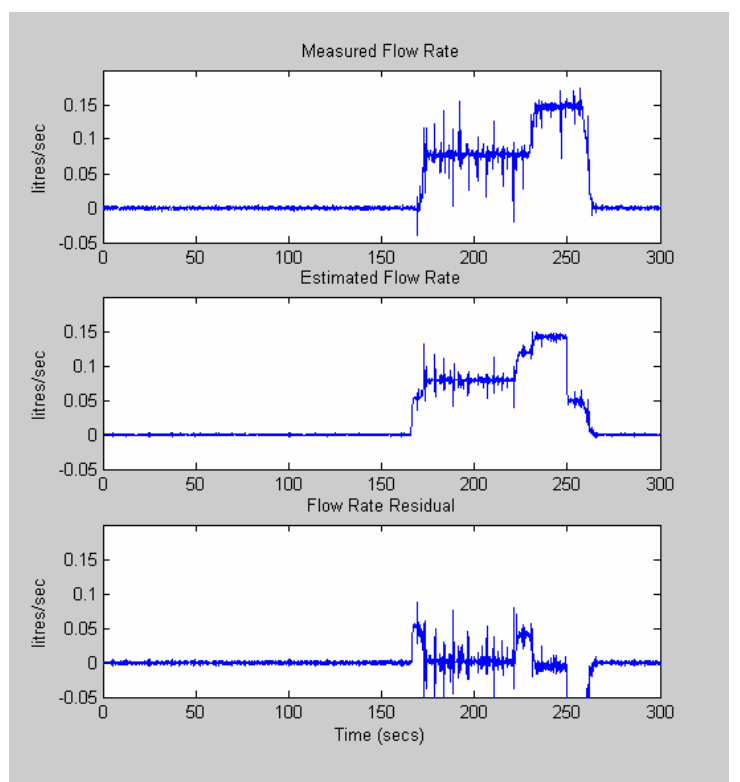

Fig 6. Measured and Estimated Main Tank Flow Rate and Residual

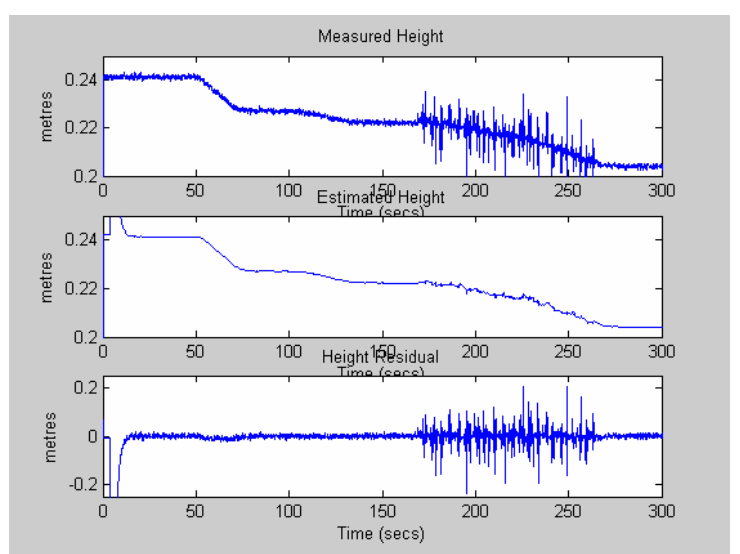

Fig 7. Measured and Estimated Main Tank Height and Residual

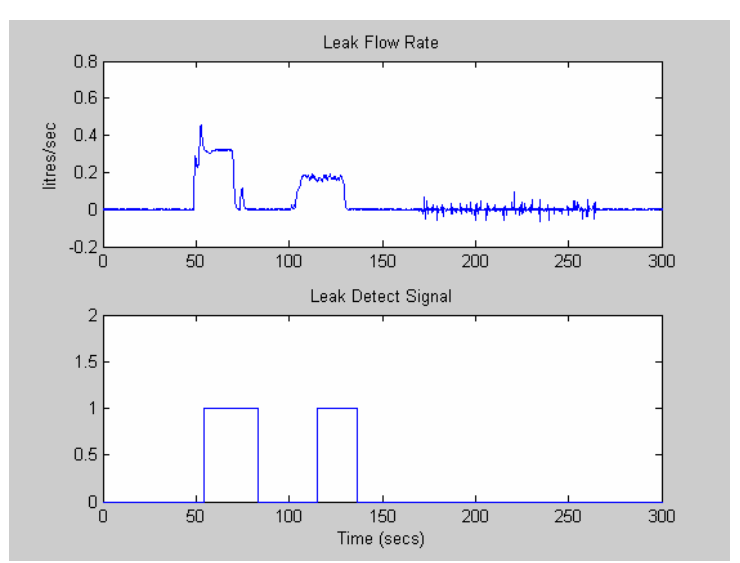

Fig 8. Main Tank Leak Flow Rate and Leak Detection Signal

\section{CONCLUSIONS}

This paper has described an Advanced Diagnostic Test-bed which has been designed to be used as part of a larger project for the assessment of various fault diagnostic tools and techniques. The project is in its early phases but the ADT has been successfully commissioned and some initial work has been started on the implementation of fault diagnostic schemes. The first scheme to be investigated uses a Kalman Filter to generate residuals and to estimate error states, the next stages of the research project will investigate the use of Neural Networks and other techniques [Venkatasubramanian 2003] for fault diagnostics.

\section{REFERENCES}

Frank, P.M., (1987). Fault diagnosis in dynamic system via state estimation - a survey. In System Fault Diagnostics, Reliability \& Related Knowledge-based Approaches. (Tzafestas, Singh and Schmidt, Eds.). Vol. 1, D.Reidel Press Dordrecht

Frank, P.M., (1997). A survey of robust residual generation and evaluation methods in observer based fault detection systems. In IFAC Jounral of Process Control. Vol. 7, pp403-424

Gertler, J.J., (1998). Fault Detection and Diagnosis in Engineering Systems. In Marcel Dekker New York

Isermann, R., (1984). Process fault detection based on modelling and estimation methods: A survey. In Automatica. Vol. 20, No. 4, pp387-404

Patton, R.J., (1991). Fault detection and diagnosis in aerospace systems using analytical redundancy. In IEE Computing and Control Engineering Journal. Vol. 2, No. 3, pp127-136

Patton, R. J., (1997) Fault Tolerant Control:-The Situation, Safe Process 1997, Hull, UK

Patton, R.J., Chen, J.,(1997). Observer-based Fault Detection and Isolation: Robustness and Applications. In Control Engineering Practice. Vol. 5, No. 5, pp671-682

Patton, R.J., Frank, P.M., and Clark, R.N., (2000). Fault diagnosis in dynamic systems: Theory and application. In London: Prentice-Hall

Willsky, A.S., (1976). A survey of design methods for failure detection in dynamic systems. In Automatica. Vol. 12, No. 6, pp601-611

Venkatasubramanian, V., Rengaswamy, R., Yin, K., and Kavuri, S., (2003). A review of process fault detection and diagnosis Part I: Quantitative model-based methods. In Computers and Chemical Engineering. Vol. 27, pp293-311

Venkatasubramanian, V., Rengaswamy, R., and Kavuri, S., (2003). A review of process fault detection and diagnosis Part II: Qualitative models and search strategies. In Computers and Chemical Engineering. Vol. 27, pp313-326

Venkatasubramanian, V., Rengaswamy, R., Yin, K., and Kavuri, S., (2003). A review of process fault detection and diagnosis Part III: Process history based methods. In Computers and Chemical Engineering. Vol. 27, pp327-346 